\title{
DEMANDA E POLÍTICAS PÚBLICAS PARA O ENSINO SUPERIOR NOS BRICS'
}

\author{
Simon Schwartzman*
}

\begin{abstract}
Este artigo analisa a expansão do ensino superior nos países chamados BRICS. A aspiração crescente pelo ensino superior obriga os governos a gerir os custos de funcionamento desse sistema. As respostas de cada país variam com sua história, cultura e regime político. Todos eles enfrentam problemas semelhantes, como escassez de recursos e o poder político de atores do sistema de ensino superior e fora dele. Cinco dilemas se apresentam aos países: 1) expansão, igualdade de acesso e diversificação das matrículas, taxas de participação, o número e os tipos de instituições; 2) limitações financeiras; 3) regulação do ensino superior privado; 4) como fazer com que as instituições de ensino superior prestem mais contas a seus alunos, funcionários e à sociedade como um todo; e 5) qualidade e relevância social da aprendizagem e pesquisa em instituições de ensino superior. Utilizando dados e evidências das pesquisas mais recentes, o artigo mostra respostas comuns, com algumas exceções em cada caso: diversificação institucional; políticas de ação afirmativa; crescimento das matrículas nas ciências sociais, humanidades, profissões sociais e Educação; pouco sucesso nas políticas de internacionalização.

PAlAvRAS-CHAvE: Ensino Superior. BRICS. Igualdade de acesso. Financiamento ensino superior. Qualidade ensino superior.
\end{abstract}

$\mathrm{O}$ acesso ao ensino superior cresceu drasticamente no mundo inteiro desde a Segunda Guerra Mundial. Em 1900, havia cerca de 500 mil alunos no ensino superior em todo o mundo, e, em 2000, eram cerca de 100 milhões (Schofer; Meyer, 2005). De acordo com o Instituto de Estatística da Unesco, em 2011, eles eram 190 milhões. Entre 1940 e 1960, o número de estudantes de ensino superior em todo o mundo passou de menos de 20 para 40 por 10.000 habitantes. Entre 1960 e 1980, essa proporção mais que dobrou, passando a 85; e dobrou de novo em 2000, ultrapassando 160 por 10 mil.

Essa expansão é algumas vezes explicada pela crescente demanda por capital humano de alta qualidade nas economias modernas, mas essa interpretação funcionalista é insuficiente. A expansão ocorreu tanto nas

\footnotetext{
* Instituto de Estudos do Trabalho e Sociedade no Rio de Janeiro. Praia do Flamengo 100, Cobertura. Flamengo. Cep: 22210030. Rio de Janeiro - Rio de Janeiro - Brasil.

simon@schwartzman.org.br

${ }^{1}$ Este artigo é uma adaptação de "Demand and policies for higher education" em Pundy Pillay, Romulo Pinheiro e Simon Schwartzman (Eds), Higher Education in the Brics Countries: Investigating the pact between higher education and society, Springer, 2015. Foi apresentado no Seminário Internacional sobre Democratização do Ensino Superior, realizado no PPGSA/UFRJ em novembro de 2013 Tradução de Micheline Christophe, revisão do autor.
}

economias desenvolvidas como naquelas em desenvolvimento; a maior parte desse crescimento ocorre em áreas não técnicas, tais como as profissões sociais e humanidades; e, em muitos países, os formados no ensino superior estão encontrando dificuldades de conseguir empregos e têm de aceitar ocupações menos qualificadas ou migrar para outros países. Ainda assim, os retornos privados do ensino superior, expressos nas diferenças salariais com aqueles que atingiram apenas o ensino secundário, tendem a ser maiores nos países em desenvolvimento que em economias maduras, tornando muito concretos os incentivos para se completar o ensino superior.

Resumindo a análise detalhada das evidências mundiais, Shofer e Meyer (2005, p. 900) apresentaram como explicação a combinação de diferentes fatores. Para eles, após a Segunda Guerra Mundial, um novo modelo de sociedade foi institucionalizado, "[...] refletido em tendências de aumento da democratização, dos direitos humanos, cientifização e planejamento do desenvolvimento. Essa mudança global institucional e cultural abriu o caminho para a hiperexpansão do ensino superior". 
De fato, a expansão da democratização e dos direitos humanos, associada ao crescente acesso à comunicação de massa, minou a tradicional aceitação por parte das pessoas de que as sociedades fossem naturalmente estratificadas em termos de riqueza e oportunidades, de que cada pessoa tivesse um lugar predefinido na hierarquia social, e de que o conhecimento e a sabedoria fossem um monopólio de poucos. Agora, todos podem aspirar a tudo, e a educação é percebida como um canal de mobilidade social e equidade. Mas "cientifização", ou seja, a crescente crença na importância do conhecimento científico e técnico para melhorar as políticas públicas e o crescimento da riqueza, não significa que as sociedades modernas exijam que todos se tornem cientistas. O "planejamento do desenvolvimento" - a noção de que as sociedades devem planejar sua economia e, consequentemente, o desenvolvimento de seus recursos humanos - foi adotado inicialmente na União Soviética e, mais tarde, em outros estados comunistas, e, até certo ponto, foi copiado em alguns países como a França e o Brasil, mas nunca adquiriu muita relevância, com exceção, por certo período, das economias planificadas. Essas noções não levaram a uma demanda significativa por educação superior para formar mais cientistas e planejadores, mas ajudaram a 늘 difundir a percepção geral de que as sociedades precisam dar mais apoio às instituições de ensino superior e possibilitar sua expansão.

Talvez mais importante do que qualquer outro fator tenha sido o extraordinário crescimento econômico da Europa Ocidental e dos Estados Unidos logo após a Segunda Guerra † Mundial. Associado à expansão do Estado de $\therefore$ Bem-Estar, esse crescimento criou uma onda de i otimismo que varreu a maior parte do mundo. Se os países desenvolvidos podiam fazê-lo agora, então, com certeza, os países em desenvolvimento poderiam e deveriam também fazê-lo em um futuro próximo. Como Tony Judt descreveu:

O Estado lubrificou as rodas do comércio, da política e da sociedade de várias maneiras. E foi responsável, direta ou indiretamente, pelo emprego e remu- neração de milhões de homens e mulheres que, assim, tinham grande interesse nele, seja como profissionais ou burocratas. Os graduados das principais universidades da Grã-Bretanha, como seus contemporâneos nas grandes écoles francesas, geralmente procuravam emprego, não em profissões do setor privado, muito menos na indústria e no comércio, mas em educação, medicina, serviços sociais, direito público, monopólios estatais ou na administração pública. Ao final da década de 1970, 60\% de todos os diplomados na Bélgica estavam empregados no serviço público ou no setor social subsidiado publicamente. O Estado europeu tinha forjado um mercado excepcional para os bens e serviços que poderia proporcionar. Ele criou um círculo virtuoso de emprego e influência que atraiu um reconhecimento quase universal (Judt, 2006, p. 362).

Essa crença no valor crescente da educação foi disseminada no mundo em parte pelo exemplo do que ocorria nos países centrais, e, em certa medida, também pela influência de instituições multilaterais como UNESCO e Banco Mundial, de instituições privadas como as Fundações Ford e Rockefeller e de muitas agências de cooperação internacional criadas nos países desenvolvidos após a Segunda Guerra Mundial, ${ }^{2}$ as quais difundiam e davam apoio à expansão da educação nos países do chamado terceiro mundo. Para muitas dessas agências, a prioridade não era o ensino superior como tal, mas a alfabetização básica e o ensino secundário, mas, à medida que a educação básica aumentava, cresciam também, em toda parte, as demandas e aspirações por níveis mais elevados de estudo.

A expansão da educação superior significou não só que mais e mais pessoas entraram no ensino superior, mas também que elas queriam ter acesso a diplomas universitários, em detrimento do ensino profissional e técnico, considerado de menor prestígio e remuneração. A consequência foi uma tendência a um "viés acadêmico", com diferentes tipos de instituições empenhando-se em obter o status de universidade para si e para seus alunos (Nea-

${ }^{2}$ Alguns exemplos: CIDA no Canadá, ORSTOM e a Agência Francesa de Desenvolvimento na França, GTZ na Alemanha, USAID nos Estados Unidos, DFID no Reino Unido, SIDA na Suécia, entre outras. 
ve, 1979; Van Vught, 2008). Elas aspiravam não só aos diplomas, mas também ao mercado de privilégios profissionais associados a suas qualificações formais, e consideravam o acesso ao ensino superior como um direito a ser provido pelos governos, se possível de forma gratuita. Em sociedades marcadas por clivagens culturais, étnicas e linguísticas, a busca pelo acesso ao ensino superior, muitas vezes, tomou a forma de demandas por compensação cultural e étnica ou apoio especial para corrigir as clivagens históricas tantas vezes relacionadas com o acesso desigual às oportunidades de educação.

A combinação entre o otimismo crescente, a crença generalizada na importância da educação e a atuação das instituições de cooperação internacional explica por que a expansão do ensino superior se tornou um fenômeno universal, embora com tempos e intensidades diferentes, e levando a diferentes respostas.

Nenhum governo poderia atender a todas essas aspirações, não só por causa de seu crescimento e custos ilimitados, mas também porque a educação é, em grande medida, um bem "posicional", no sentido de que as vantagens de alguns dependem de sua posição relativa na hierarquia educacional em relação aos outros (Hollis, 1982; Brown, 2003). Embora a posição social, os benefícios e oportunidades de trabalho criados por níveis mais elevados de educação sejam, em boa parte, uma função dos privilégios concedidos àqueles que possuem credenciais educacionais de mais prestígio (Collins, 1979), eles dependem também, no longo prazo, da produtividade do titular e da vontade da sociedade de pagar por essas credenciais. Com o aumento da demanda por ensino superior, os governos tiveram de prestar mais atenção a seu custo e aos benefícios que ele traz para a sociedade.

As respostas de cada país variaram de acordo com a história, cultura e regime político, mas todos tiveram de enfrentar problemas semelhantes, incluindo a escassez de recursos e a necessidade de se certificar de que o di- nheiro público e o privado não estavam sendo desperdiçados em uma pirâmide de grandes dimensões. Eles tiveram também de lidar com o poder político e a influência de acadêmicos, estudantes e funcionários públicos, muitas vezes organizados em sindicatos e associações e com fortes ligações com governos locais, partidos políticos e movimentos sociais. Em todos os países, os governos oscilaram entre conceder mais autonomia às universidades, ou submetê-las a controles mais rígidos; entre pressioná-las a buscar recursos no mercado, ou fornecer-lhes mais recursos públicos; entre atribuir a todas as mesmas funções, ou selecionar algumas instituições para missões mais elevadas com mais recursos públicos; entre exigir delas uma ligação mais forte com o sistema produtivo, ou permitir que elas próprias definam seus objetivos e orientações de ensino e pesquisa. É possível resumir os dilemas de política pública em cinco grandes temas: 1) como lidar com a expansão, a igualdade de acesso e a diversificação das matrículas, as taxas de participação, o número e os tipos de instituições; 2) como lidar com as limitações financeiras, particularmente em períodos de estagnação ou declínio econômico; 3) como regular o crescente mercado de ensino superior privado; 4) como fazer com que as instituições de ensino superior prestem mais contas a seus alunos, funcionários e à sociedade como um todo; e 5) como melhorar e manter a qualidade e a relevância social da aprendizagem e da pesquisa (Johnstone et al., 1998, p. 2). Nas sessões seguintes, examinaremos, com algum detalhe, como Rússia, China, África do Sul, Índia e Brasil - os países BRICS - vêm enfrentando essas questões.

\section{RÚSSIA}

Enquanto Brasil, China, Índia e África do Sul começaram a expansão do ensino superior a partir de uma base muito pequena, a Federação Russa herdou da União Soviética 
um sistema de ensino superior muito desenvolvido, que foi profundamente transformado depois 1990 e se tornou mais semelhante ao de outros países.

A União Soviética foi, talvez, a tentativa mais extrema já havida de gerir o ensino superior por meio do planejamento de recursos humanos, de acordo com a visão funcionalista da educação superior como fator de produção. A maioria das instituições de ensino superior estava ligada a setores específicos de atividade, e o governo estabelecia o que devia ser produzido e por quem e qual seria a mão de obra necessária para alcançar os resultados desejados. Deu-se prioridade aos cursos técnicos, mas as ciências humanas também tiveram lugar. Conforme é descrito por Isak Froumin e Yaroslav Kouzminov, “[...] cada desenvolvimento importante na economia nacional, bem como a vida social e política, foi acompanhado por um desenvolvimento correspondente no setor do ensino superior"

Isso significou também que, em princípio, os alunos não tinham de procurar emprego: eles eram designados para trabalhar na região e no setor em que se formavam, sem muita escolha. Esse arranjo funcional estava associado a uma hierarquia clara das universidades: havia universidades setoriais nacionais, liga는 das a ramos específicos da economia (transporte, mineração etc.), muitas vezes subordinadas aos ministérios setoriais correspondentes; universidades setoriais regionais, ligadas às suas respectivas instituições nacionais; e universidades mais tradicionais, destinadas a formar as elites políticas locais e os professores. Em \& termos comparativos, o tamanho do setor de \& ensino superior soviético não era muito dife-

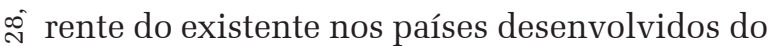

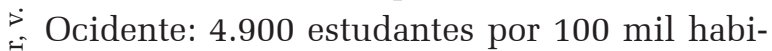
tantes, em 1990, em comparação com 4.000, no Canadá, 3.400, na Finlândia, 3.500 no Reino Unido e 5.000 nos Estados Unidos (Dados do Instituto de Estatística da UNESCO).

Na década de 1980, esse arranjo complexo já estava desgastado, devido a falhas do planejamento centralizado. Com o colapso da União Soviética e a introdução da economia de mercado, o governo russo teve de reinventar a educação superior, como é descrito por Mark S. Johnson, em um comportamento errático que passou de tentativas de conceder total autonomia às universidades, mas deixando-as abertas à concorrência de mercado, até as tentativas de recuperar o controle total, centralizado, do setor de ensino superior. O fim do planejamento centralizado significou não só redução do montante de dinheiro para apoiar o ensino superior como também o reconhecimento de que a abordagem tradicional de planejamento de recursos humanos não podia mais ser usada na definição de prioridades para orientar a alocação dos recursos.

Nos primeiros dez anos após a Perestroika, o governo russo permitiu que o setor do ensino superior se expandisse com pouco ou nenhum esforço de conduzi-lo a uma direção específica, sem muita interferência e com apoio decrescente. Entretanto, depois de 2000, sob a presidência de Putin, o ensino superior ganhou mais prioridade, absorvendo 23,1\% das despesas de educação do país, contra $16,1 \%$ em 2000, enquanto a despesa por aluno, em porcentagem do PIB per capita, passou de $10,9 \%$ para $14,2 \%$ (dados do Instituto de Estatística da UNESCO). A nova ênfase estava associada a várias tentativas de introduzir mecanismos de garantia de qualidade e de aumentar o papel do governo central na condução do setor do ensino superior. As novas medidas incluíram uma diferenciação nítida entre as instituições federais e locais, a criação de um exame de entrada unificado para o ensino superior em áreas específicas, e fundos competitivos para pesquisa e instituições inovadoras. As instituições também foram estimuladas a trabalhar em conjunto com empresas públicas e privadas do setor produtivo, a introduzir práticas gerenciais empresariais e a procurar fontes adicionais de recursos, além dos provenientes de fontes governamentais. Nos últimos anos, o governo evoluiu para a criação de um 
sistema de três níveis de instituições de ensino superior. No topo, um pequeno número de 10 a 15 universidades federais, altamente competitivas, de nível internacional. Num segundo nível, estão entre 150 e 200 universidades regionais, apoiadas principalmente pelos governos regionais; e um terceiro nível de instituições que foram deixadas à sua própria sorte e, eventualmente, fadadas ao desaparecimento. Houve também um movimento de vincular as principais universidades com os institutos de pesquisa que, na União Soviética, faziam parte da Academia de Ciências e, por fim, para trazer a Rússia para mais perto da Europa, o país aderiu ao Processo de Bolonha de reforma do ensino superior.

Gráfico 1 - Rússia, matrículas no ensino superior (1971-2009)

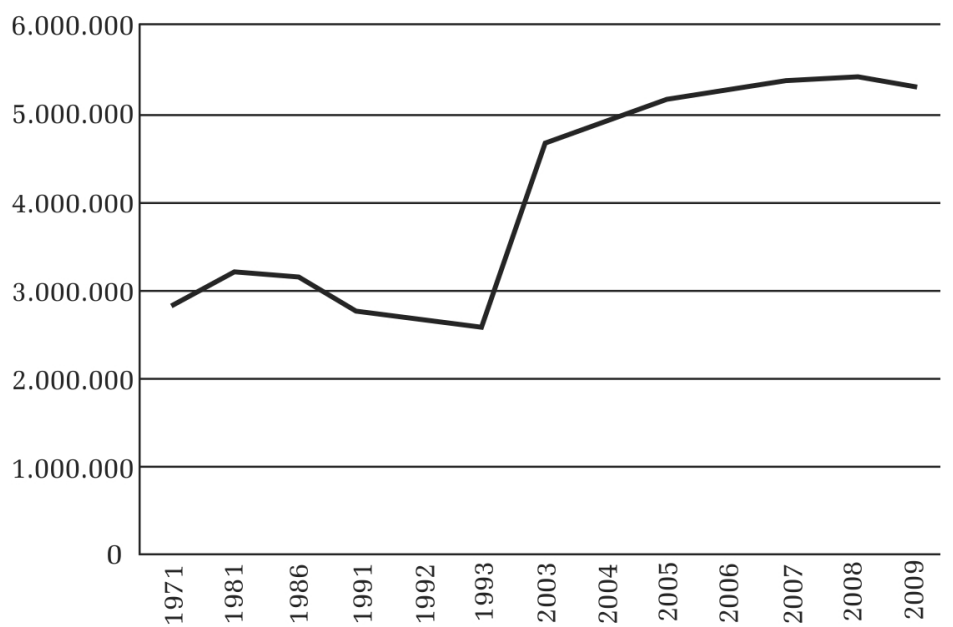

Fonte: Instituto de Estatística da Unesco

Enquanto, no período soviético, a maioria dos alunos era direcionada aos estudos de engenharia, produção e construção, agora, cerca de metade deles estão na área de humanas, ciências sociais, negócios e direito. Em média, um diploma universitário ainda significa um aumento significativo dos salários em comparação com os salários daqueles que só têm o ensino secundário (98\% para os homens, 55\% para as mulheres, de acordo com uma estimativa) (Gerber; Schaefer, 2004), além de uma proteção contra o desemprego, o que significa que a demanda por ensino superior não ten- de a diminuir. No entanto, existem diferenças importantes em função do prestígio das instituições, da área e especialidade dos estudos e do sexo, fatores que resultam em benefícios mais altos para os homens capazes de serem admitidos em instituições de maior prestígio e estudarem em tempo integral e gratuitamente.

A Federação Russa é uma sociedade multinacional, com quase duas centenas de grupos étnicos reconhecidos e mais de 50 línguas minoritárias. Seria de se esperar a existência de grandes diferenças no acesso ao ensino superior por parte de membros das minorias não russas e dos moradores de regióes distantes, especialmente, no ingresso nas universidades de maior prestígio de Moscou e São Petersburgo. No entanto, as estatísticas e documentos existentes relacionados ao ensino superior na Rússia raramente mencionam essas diferenças, dando uma imagem de homogeneidade social e equidade de acesso que é claramente enganosa.

A educação superior na Rússia está em fluxo, e não se sabe como irá evoluir. Para Mark S. Johnson, que realizou uma análise detalhada das diferentes mudanças e políticas em curso nesse país, [...] o efeito cumulativo destas iniciativas ambiciosas de reforma e novos investimentos do Estado é que, embora a 'modernização’ do ensino superior da Rússia não seja nem tão coerente, nem tão bem sucedida como as autoridades russas e os líderes universitários muitas vezes parecem afirmar, há mudanças setoriais significativas em curso que poderiam se mostrar transformadoras nos próximos anos. Se bem sucedidas, as universidades reformadas poderiam desempenhar um papel de liderança à medida que a Rússia conquista seu próprio caminho distintivo de (re) modernização e integração à economia global, desde, é claro, que os problemas crônicos da Rússia de poder burocrático autoritário, isolamento intelectual, sectarismo clientelista e corrupção institucional possam ser mitigados ou superados. 


\section{CHINA}

A China tem uma história importante de cultura erudita na tradição confucionista, que se manifestava nos concursos para o serviço público, restritos a um segmento muito pequeno de mandarins. A partir de 1911, com a República, o governo nacionalista desenvolveu um sistema moderno de universidade que, até o final da Segunda Guerra Mundial, era composto por 141 instituições de ensino superior, com 84 mil alunos matriculados.

Depois da Segunda Guerra Mundial e com a vitória do Partido Comunista na Guerra Civil, a República Popular da China adotou o modelo soviético de planejamento central e de educação funcional, substituindo as instituições do período nacionalista. Para a maioria da população que vivia em áreas rurais e trabalhava na agricultura, o acesso à educação manteve-se muito limitado. Com a Revolução Cultural de 1966-1968, a maior parte da nova elite educada que tinha surgido com o novo regime perdeu seu emprego e foi enviada para "campos de reeducação" em áreas rurais, todo o ensino médio e superior foi fechado e só foi reaberto em 1972 (Deng; Treiman, 1997). Em 1973, havia apenas cerca de 200 mil alunos no ensino superior no país, segundo o Instituto de

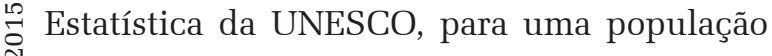
$\therefore$ que se aproximava de um bilhão de pessoas, conforme relatado pelo Censo de 1982, das quais $80 \%$ viviam no campo.

Nos anos seguintes, e particularmente após as reformas de liberalização introduzi$\stackrel{\circ}{\circ}$ das por Deng Xiaoping depois de 1979, o país + começou a mudar drasticamente. Em 1990, ¿ $26 \%$ da população viviam em áreas urbanas; N em 2000, 36\%; em 2010, o número de habitan$\vec{t}$ tes das cidades ultrapassou os do campo. Essa migração de centenas de milhões de pessoas do campo para a cidade ocorreu por causa das novas oportunidades de vida surgidas nas cidades graças às reformas econômicas, desde o final da década de 1970, com a criação de uma economia de mercado que estimulou a iniciati- va privada. Pesquisadores chineses costumam atribuir essas mudanças às decisões de políticas públicas da liderança do Partido Comunista, mas é improvável que a China pudesse permanecer para sempre isolada das mudanças globais de urbanização, industrialização e educação que estavam acontecendo em toda parte. O que a liderança política faria, e fez, foi tentar orientar este processo, tanto quanto pôde, preservando seu poder.

O ensino superior se expandiu muito rapidamente com a urbanização e a industrialização. Em 1980, já havia um milhão de estudantes; dez anos depois, já eram 4 milhões. O primeiro movimento do governo chinês para a reforma do setor de ensino superior ocorreu em 1985, mas só começou a ser implementado em 1993, com o lançamento do "Projeto de Reforma da Educação e Desenvolvimento na China”, quando a transformação já estava em andamento (Cai; Yan). Essa reforma consistiu, basicamente, em permitir que as instituições admitissem mais alunos e na transferência de responsabilidades pelo ensino superior às autoridades locais; desde 1997, também passou a permitir que as instituições públicas cobrassem mensalidades dos estudantes, o que criou incentivos para que elas expandissem ainda mais as suas matrículas. Desde então, as matrículas crescem exponencialmente, chegando a 9,3 milhões em 2001 e a cerca de 31 milhões em 2010.

Qiang Zha e Ruth Hayhoe consideram que,

[...] em geral, as universidades chinesas são muito mais estreitamente articuladas com os planos e estratégias nacionais e locais de desenvolvimento do que suas homólogas ocidentais. As universidades chinesas são, em grande medida, o braço educacional e de pesquisa do governo para o desenvolvimento econômico e social [...]

Adota-se, assim, a abordagem funcional de política de educação que parece ter sido abandonada em outros lugares. Essa pode ter sido a linha oficial, mas, na prática, o que ocorreu foi uma “[...] descentralização da direção e gestão em troca de desempenho e responsabili- 
Gráfico 2 - China, total de matrículas no ensino superior

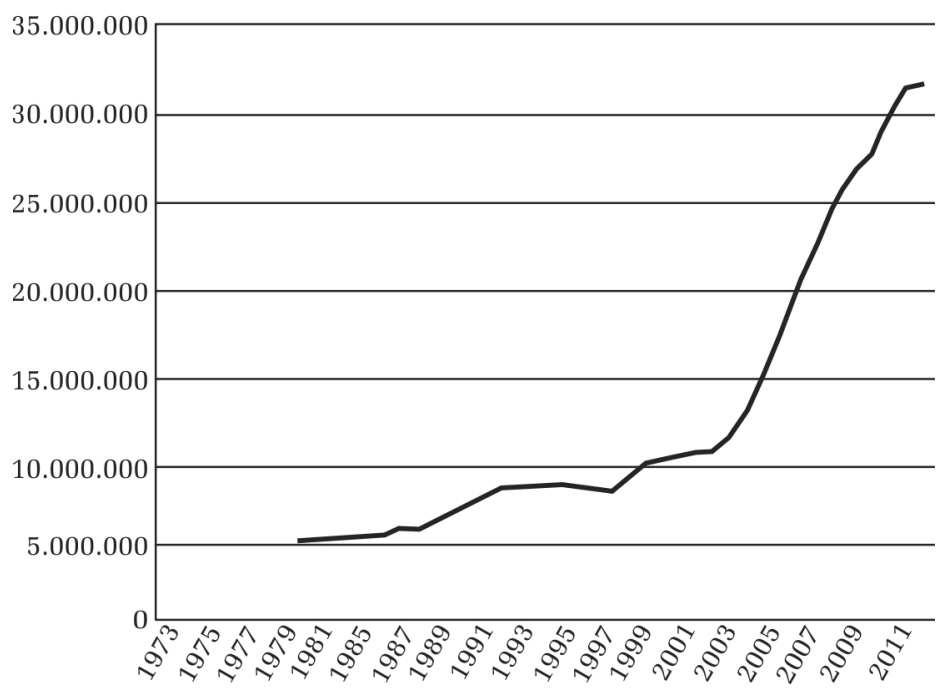

Fonte: Instituto de Estatística da Unesco

zação institucional, e ao mesmo tempo aumentando o controle sobre os critérios normativos da produção de conhecimento" (Zha; Hayhoe).

O principal instrumento para isso foi a divisão das instituições de ensino superior em quatro níveis - instituições de pesquisa, instituições de pesquisa e ensino, instituições de ensino e instituições de formação técnica para o mercado de trabalho. Além disso, cerca de cem instituições foram selecionadas em um processo competitivo para serem incluídas no chamado "Projeto 211" e passaram a receber apoio adicional, com a expectativa de que alcancem padrões mundiais no século 21. Nesse grupo, 39 universidades de excelência foram selecionadas pelo "Projeto 985", que fornece apoio financeiro em níveis semelhantes aos das instituições líderes na Europa e nos Estados Unidos, e é, em grande parte, responsável pelo aumento de artigos científicos publicados por autores chineses nos últimos anos. Outro instrumento foi a criação de um exame nacional unificado para admissão nas universidades, que segue princípios meritocráticos rigorosos e coloca os melhores alunos nas melhores universidades (isso tem uma longa história pré-49, foi posto em prática na "nova China" em 1956, foi interrompido pela Revolução Cul- tural, e restaurado em 1977).

Apesar de todo esse crescimento no setor público, observa-se que as instituições privadas também estão se expandindo, e que muitos estudantes chineses preferem estudar no exterior, se puderem. Em 2011, havia cerca de 700 universidades privadas no país, com mais de 5 milhões de alunos, cerca de $22 \%$ do total de matrículas. Essas instituições também estão sob supervisão das autoridades governamentais. As universidades privadas atraem em grande parte estudantes que não conseguem entrar nas universidades públicas, ou que optam por uma universidade particular em uma cidade mais conveniente ou com programas atraentes, ao invés de uma universidade pública de menor nível em uma área mais remota. A China é também o país com o maior número de estudantes no exterior. De acordo com o Ministério da Educação da China, no final de 2011, o número total de estudantes no exterior havia alcançado 2.244.100, e o percentual de retornados foi de apenas $36 \%{ }^{3}$

Claramente, a China tem sido muito bem sucedida na expansão de seu setor de ensino superior, e os eventuais problemas de qualidade e de acesso que podem existir são difíceis de avaliar a partir da literatura existente. Quanto ao acesso, existem 56 grupos étnicos oficialmente reconhecidos no país e cerca de 300 línguas. A maioria da população pertence ao grupo Han e fala mandarim, além de um dialeto local, como, por exemplo, o cantonês; mas há, pelo menos, 15 outros grupos com mais de um milhão de membros. A China conta com um sistema muito complexo de ação afirmativa que oferece vantagens para certos grupos no acesso à educação superior, incluindo instituições especializadas para minorias, cotas e pontuação adicional para estudantes ${ }^{3}$ http://en.ccg.org.cn/_d275923658.htm 
de minorias nos exames das universidades nacionais (Sautman, 1998; Postiglione, 1999). ${ }^{4}$ Ainda que essas políticas resultem em benefícios para os estudantes de grupos minoritários que, de outra forma, não teriam chance de ingressar no ensino superior, eles continuam sub-representados nesse nível de ensino.

Quanto à qualidade do ensino superior, há uma percepção de que os cientistas e profissionais chineses são bem treinados, mas que lhes faltariam iniciativa e criatividade, o que é atribuído tanto à tradição confucionista, que prioriza a autoridade e a disciplina sobre o pensamento crítico e independente, como à tendência para a especialização estrita, herdada da visão funcionalista do ensino superior que ainda prevalece no país, como resultado da influência soviética inicial (Zha; Hayhoe). É difícil, todavia, dizer até que ponto isso é verdade.

\section{ÍNDIA}

Como Rússia e China, a Índia é um país de grandes dimensões, com centenas de diferentes etnias e línguas, e um forte sistema de castas que há séculos mantém a mobilidade social no mínimo.

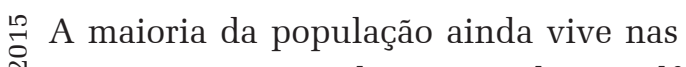
: áreas rurais, cerca de 30\% ainda é analfabeta, e o país nunca passou por períodos de industrialização e de urbanização intensos como os que, por exemplo, mudaram a China tão ָิ profundamente nas últimas décadas. No vasণ to subcontinente indiano, o Império Britânico $\underset{\sim}{*}$ criou uma grande burocracia administrativa e \& ofereceu às elites indianas oportunidades de

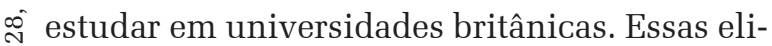
$\vec{t}$ tes foram depois responsáveis pelo movimento de independência e pela organização do Esta-

${ }^{4}$ Como observado por Sautman, admissões preferenciais - são praticadas principalmente por instituições para as mi-

I. norias. Embora muitas instituições, predominantemente

ک Han, de ensino superior também participem de ação afir-

$\supsetneq$ mativa, a maioria das admissões preferenciais dificilmen-

te, ou nunca, diminuem as oportunidades dos estudantes

Han, uma vez que o ensino superior como um todo conti-

nua a se expandir (Sautman, Barry, 1998 p. 106). do moderno no país. Em 1950, a Índia tinha apenas 200 mil pessoas com ensino superior, para uma população de cerca de 400 milhões de pessoas. Em 1970, as matrículas mais que triplicaram, chegando a 2 milhões, atingindo cerca de 9 milhões em 2000 e 22 milhões em 2012. A taxa de escolarização bruta, de 18,8\%, ainda é pequena em termos comparativos, mas é um dos maiores sistemas de ensino superior do mundo, com cerca de 35 mil instituições de todos os tipos. Cerca de $20 \%$ dos alunos de graduação fazem cursos de engenharia, com o restante nas artes, profissões sociais e de ensino, entre outros (India's University Grants Committee, 2013).

Gráfico 3 - Índia, matrículas no ensino superior (milhões)

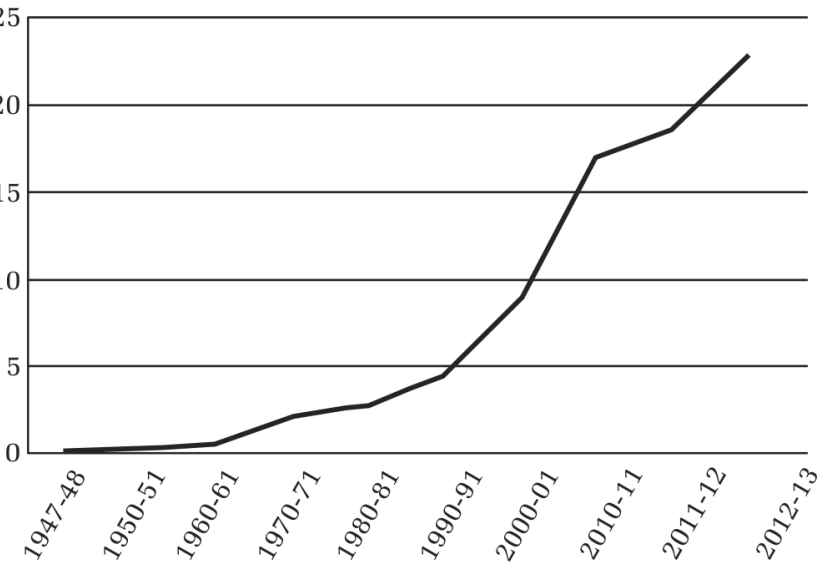

nte: India's University Grants Committee, 2013

Enquanto, na China, a maioria dos privilégios sociais tradicionais associados à educação foi eliminada com a Guerra Civil e a Revolução Cultural, na Índia, as desigualdades sociais relacionadas com riqueza, etnia, casta e sexo se mantiveram após a independência e tornaram-se centrais para todas as políticas de ensino superior que foram apresentadas ou implementadas pelos governos democráticos desde então. Ao mesmo tempo, como em outros lugares, o governo precisou lidar com a proliferação de instituições, a limitação de recursos e problemas de garantia da qualidade, em um ambiente político extremamente complicado, marcado por uma oposição ativa e estados fortes e autônomos. 
A proliferação de instituições foi tratada a partir de um reconhecimento formal de que nem todas as instituições de ensino superior são iguais. Além da distinção entre universidades e colleges (semelhante à diferenciação existente nos Estados Unidos e na Inglaterra), as universidades são divididas em centrais, estaduais, instituições "reconhecidas" (criadas por decreto, e não por legislação estadual), e, com exceção das instituições nacionais, podem ser públicas ou privadas. Das 690 universidades existentes, 48 são centrais, 60 são consideradas de importância nacional, e as restantes são ou privadas ou dirigidas pelos governos estaduais (Joshi)

Quanto ao gasto público no ensino superior, ele é de cerca de 1,2\% do PIB, o que, embora não seja pequeno para os padrões internacionais, está longe de ser suficiente, devido à dimensão do setor. As universidades públicas, embora autorizadas a cobrar mensalidades dos estudantes, não conseguem mais que $10 \%$ do total de seus recursos com essa fonte de renda. Isso significa que a maioria delas, especialmente no nível estadual, está subequipada, e os salários dos docentes estão entre os mais baixos do mundo (Rumbley; Pacheco et al., 2008).

Ao mesmo tempo, as instituições de ensino superior privadas estão se expandindo rapidamente, matriculando quase $60 \%$ dos alunos. Como é descrito por Roopa Desai e Sheila Embleton,

A educação superior privada na Índia se expandiu na prática, embora não de direito. O setor cresceu muito rápido e agora é responsável por $2 / 3$ de todas as faculdades, $4 / 5$ de todas as escolas profissionais e 1/3 dos colleges de formação geral. O impacto do crescimento das instituições de ensino superior privadas é maior em programas profissionais, onde, por exemplo, as faculdades de engenharia privadas, que respondiam por $15 \%$ de todas as faculdades de engenharia, em 1960, chegaram a representar 86\%, em 2003. Da mesma forma, as faculdades de medicina privadas passaram de cerca de $7 \%$ a $41 \%$ do total, e as faculdades de administração privadas a cerca de $90 \%$ de todas as escolas de negócios (Trilokekar; Embleton).
Algumas dessas instituições recebem apoio do governo; outras dependem inteiramente de recursos privados que conseguem arrecadar e estão sujeitas a intensas críticas de muitos setores, em parte porque são apenas instituições de ensino, sem nenhuma pesquisa, e têm fins lucrativos. Na Índia, como em muitos outros lugares, há um entendimento de que o ensino superior é um bem público e não deve ser guiado por razões de mercado. Apesar disso, o fato é que a maioria das instituições não faz pesquisa, e o setor privado criou possibilidades de acesso ao ensino superior que o setor público não consegue prover. Hoje, assim como no Brasil, o setor privado, na Índia, é um grande negócio. Triolokekar e Embleton afirmam que, como a demanda de ensino superior e serviços relacionados excede a oferta, pode-se esperar altos retornos dos investimentos no setor. Houve um crescimento do ensino superior privado não apenas em faculdades e universidades que fornecem diplomas, mas também em serviços paralelos de ensino, escolas de formação profissional, programas de certificação e cursos preparatórios, que são muito populares. Novamente esse movimento é muito semelhante ao do Brasil, pois algumas das maiores instituições privadas tiveram sua origem em "cursinhos", estudos preparatórios pagos para os competitivos exames de admissão às universidades públicas de prestígio. Outro desenvolvimento importante e recente na Índia é a expansão da educação à distância, oferecida majoritariamente por instituições públicas, como a Universidade Nacional Aberta Indira Gandhi e as Universidades Abertas Estaduais. A estimativa é de que $22 \%$ das matrículas em instituições de ensino superior na Índia são em programas de educação à distância.

A ação afirmativa é um tema central na educação superior da Índia, com grande atenção para a relativa exclusão das mulheres e dos membros das chamadas "castas e tribos excluídas". Segundo Joshi, o governo central reservou $7,5 \%$ das vagas em instituições de ensino superior para as tribos e 15\% para as castas ex- 
cluídas. A percentagem de reserva varia entre os Estados, de acordo com a presença desses grupos. Além das cotas, o governo oferece bolsas de estudo, albergues especiais, refeições, empréstimos de livros e outros benefícios exclusivamente para os estudantes provenientes de castas e grupos excluídos, de forma a estimular a participação (Joshi). Como em toda parte, o tema de ações afirmativas gera controvérsia. Para os críticos do sistema, o acesso ao ensino superior e, particularmente, às instituições de alta qualidade e prestígio, deve depender do desempenho anterior no ensino secundário e, nessa lógica, o governo deveria investir mais na melhoria da educação geral e secundária, permitindo que o setor de ensino superior seja mais competitivo e meritocrático. Isso, em certa medida, está sendo feito, embora a qualidade da educação, em geral, ainda deixe muito a desejar. Além disso, na Índia, dada a natureza discriminatória do sistema de castas e o isolamento cultural de tribos minoritárias, só a melhoria da educação básica não seria suficiente para proporcionar igualdade de acesso ao ensino superior a pessoas pertencentes a esses grupos excluídos. Há estudos que mostram que as políticas de ação afirmativa criaram, de fato, oportunidades de acesso ao ensino superior que não existiriam de outra forma, embora também se reconheça que a maioria dos bene. ficiários das políticas afirmativas seja constituída por membros dos estratos mais altos das castas e das tribos excluídas (Weisskopf, 2004). Por outra parte, não há reservas de gênero, e as disparidades existentes, que são grandes, estão relacionadas a características culturais profun‡ das da cultura indiana, que podem variar de \& uma região para outra. importantes resultados obtidos pelo país em diferentes campos da ciência e da tecnologia de ponta, tem um sistema de ensino superior cuja qualidade é, em geral, considerada baixa. Para lidar com esse problema, o país estabeleceu, em 1994, um Conselho Nacional de Avaliação e Acreditação (Stella, 2002) e uma rede extremamente complexa de instituições de políticas públicas, muitas vezes com sobreposição de responsabilidades. Segundo a descrição de Triolokekar e Embleton, a Índia tem 13 órgãos de regulação profissional e vocacional, além do Conselho Indiano de Educação Técnica e do Comitê de Financiamento para as universidades. O grande número de órgãos, muitas vezes se reportando a outros ministérios (ou seja, não ao Ministério do Desenvolvimento de Recursos Humanos, responsável pelo ensino superior), contribui para uma estrutura de regulamentação extremamente complexa, que impossibilita o desenvolvimento de uma política coesa e coerente para o setor. Os mandatos desses órgãos reguladores são abrangentes e permitem o controle de todos os aspectos da governança institucional - financeiros, administrativos e acadêmicos. O resultado é uma falta de liberdade acadêmica e de autonomia institucional, já que muitas atividades, como a contratação de professores e administradores, a definição de salários e honorários, currículo e testes, dentre outros aspectos, são centralizados e padronizados por esses órgãos reguladores

Para a Índia, a questão da internacionalização não é nova, dado o seu passado como colônia britânica. A maioria de suas instituições é organizada de acordo com o modelo inglês, além de o inglês ser a língua oficial adotada no ensino superior. Por adotar o inglês, algumas práticas - como a instalação de instituições de ensino superior estrangeiras, a exportação de diferentes tipos de serviços para o mundo inteiro (incluindo os do extremamente bem sucedido setor de TICs) e o envio de pesquisadores indianos para estudar e trabalhar no exterior e depois voltar - tornam-se relativamente mais fáceis que em outros países.

No entanto, apenas algumas centenas de milhares de indianos têm o inglês como língua nativa. O hindi, com seus diferentes dialetos, é falado por $40 \%$ da população, e os demais falam mais de 1.600 línguas, 12 das quais com mais de 10 milhões de falantes. O domínio 
adequado de inglês, fortemente relacionado à cultura familiar e ao acesso à educação básica de boa qualidade, é um grande diferencial na sociedade indiana hoje e um forte determinante de quem tem acesso à melhor educação e aos melhores empregos.

O passado colonial e o acesso à língua inglesa ajudam a explicar também o grande número de indianos educados que vão estudar e permanecem no exterior. Em 2012, havia 200 mil alunos indianos no ensino superior no exterior, dos quais 103 mil nos Estados Unidos, ${ }^{5}$ o maior número do mundo depois da China. Esse grupo é apenas uma pequena parte da enorme diáspora indiana, que pende fortemente no sentido de pessoas altamente qualificadas. ${ }^{6}$ Segundo um relatório recente,

O número de imigrantes indianos, especialmente daqueles com qualificação, tem aumentado progressivamente. Em 2010, a Índia registrou 11,4 milhões de saídas: o segundo maior número de emigrantes, depois do México, com 11,9 milhões. Em termos absolutos, a Índia é um dos principais fornecedores de pessoal qualificado para os mercados internacionais. O capital humano qualificado do país no exterior é muito variado e abrange quase todos os campos de atividade, embora haja uma prevalência de TI e do setor médico. A Índia também é um dos principais fornecedores de uma das fontes primárias de capital humano qualificado, isto é, de estudantes. Junto com a China, é o principal exportador de estudantes internacionais ( Giordano; Terranova, 2012).

Para unificar sua política, o governo indiano recentemente apresentou uma proposta de estabelecer um órgão para o setor de ensino superior como um todo, o Conselho Nacional de Ensino Superior; o projeto, todavia, foi abandonado em 2013, após não ter obtido a aprovação do Parlamento. Os especialistas debatem se a política de ensino superior da

5 Essas informações podem ser encontradas em: http:// www.uis.unesco.org/Education/Pages/international-student-flow-viz.aspx

${ }^{6}$ Nos últimos anos, com a liberalização da economia indiana, de um lado, e a desaceleração econômica nos Estados Unidos e na Europa Ocidental, de outro, muitos indianos altamente qualificados decidiram voltar. A estimativa é que mais de 100.000 indianos voltaram à sua terra natal em 2010 (Giordano, Alfonso e Terranova, Giuseppe, 2012)
Índia está à deriva ou seguindo uma direção. Trilokekar e Embleton argumentam que

[...] um exame mais atento da política de ensino superior na Índia ao longo dos últimos cinco anos, ou mais, não confirmaria os argumentos de Tilak (Tilak, 2010) de que há um vácuo na política de ensino superior na Índia, ou de que a característica distintiva da política indiana seja na verdade a ausência de uma perspectiva política clara, coerente, explícita e de longo prazo.

Na opinião de Trilokekar e Embleton, embora o campo do ensino superior seja inevitavelmente controverso e sujeito a interesses conflitantes e, muitas vezes, a políticas contraditórias, especialmente numa sociedade democrática, há, porém, um senso de direção, marcado pela crescente centralidade de conceitos como economia do conhecimento, competitividade econômica e preocupações com as necessidades do mercado de trabalho, o que racionaliza iniciativas de políticas específicas, tais como a promoção da inovação, autonomia, privatização e investimento em universidades de nível internacional.

Uma visão mais negativa, expressa por D. Kapur e B. P. Mehta (2004), é de que o ensino superior da Índia está pendendo para a privatização, não como uma política deliberada, mas em consequência do colapso político e institucional. Para eles,

Em vez de ser parte de um programa abrangente de reforma educacional, muito da iniciativa privada permanece refém das ações discricionárias do Estado. Consequentemente, o sistema de ensino continua pendurado entre um excesso de regulação por parte do Estado, de um lado, e uma privatização discricionária que é incapaz de mobilizar o capital privado de forma produtiva. O resultado é uma estruturação deficiente do ensino superior. A consequência mais forte disto é a exclusão da classe média - ironicamente a própria classe a cujos interesses essas instituições deveriam servir - da participação nas instituições públicas (Kapur; Mehta, 2004, p. 2). 


\section{ÁFRICA DO SUL}

Mais do que na Índia, as políticas de ensino superior na África do Sul estão centradas nas questões étnicas e de ação afirmativa, por boas razões. A história da África do Sul é marcada por séculos de colonização branca e guerras, em um vasto território povoado por diferentes sociedades africanas que culminaram no projeto de Apartheid que, entre 1970 e 1993, levou ao extremo o projeto de construção de um estado-nação moderno, baseado na dominação de um grupo sobre outros e na discriminação.

A África do Sul, sob o apartheid, não era composta por "duas nações" que viviam separadamente, mas por uma sociedade com relações complexas e hierarquias fortes entre os diferentes setores da população. Enquanto grande parte da população africana era marginalizada e contida em suas "terras natais", outros foram trazidos para trabalhar na moderna economia criada pelos colonos brancos e tinham acesso limitado a serviços sociais, incluindo a educação.

A primeira universidade sul-africana, a Universidade do Cabo da Boa Esperança, foi criada em 1873 e, em 1918, foi incorporada à Universidade da África do Sul, Seguiram-se as 늘 Universidades de Rhodes, de Witwatersrand (1922) e, mais tarde, as de Natal, Pretoria, Potchefstroom e Free State. A maioria dos estudantes dessas universidades era branca, e a principal alternativa para os negros e mestiços dispostos a continuar sua educação era a Uni$\stackrel{\circ}{\circ}$ versidade de Fort Hare, estabelecida por mis+ sionários cristãos em 1916. Começando com \& a Lei de Educação Bantu de 1953, o governo i sul-africano criou um Departamento de Educação Negra, alojado no Departamento de Assuntos Nativos, o que levou, em 1959, à criação de instituições de ensino segregadas para negros, ${ }^{7}$ o que limitava também o acesso dos

${ }^{7}$ Trata-se, por exemplo, das seguintes instituições: Universidade do Norte, Universidade da Zululândia, Universidade de Medicina da África do Sul, Universidade de Vista, Mangosotho Technikon e Technikon Northern Transvaal. não brancos às universidades tradicionais. Até o final do apartheid, em 1994, a África do Sul tinha 21 universidades públicas e 15 escolas técnicas (Technikons), algumas para anglofalantes brancos, outras para africânderes (também brancos), uma para mestiços e outras para a população negra.

A expectativa dos governantes brancos era de que as instituições segregadas formariam uma elite negra que seria devidamente treinada e submissa ao regime político. Os bush colleges, no entanto, tiveram o efeito oposto: como mais africanos entraram no ensino superior, essas faculdades tornaram-se o terreno fértil para a mobilização estudantil e o ativismo contra o regime do apartheid. Segundo a descrição de Thiven Reddy, em seu relatório de 2004 para o Conselho de Educação Superior,

O desenvolvimento das universidades negras aumentou o número de estudantes, e as culturas repressivas e conservadoras dentro dessas instituições não conseguiram estabelecer com sucesso o controle social, de acordo com as visões dos arquitetos do planejamento do ensino superior. Ironicamente, o crescimento do número de estudantes universitários negros entre 1960 e 1976 estudando em cursos de ciências humanas e educação, as condições repressivas nos campi negros e a postura conservadora do corpo docente criaram as condições que contribuíram para a agitação estudantil. Após um período inicial de passividade, a crescente frustração e alienação dos estudantes produziram organizações estudantis e campanhas por reformas universitárias (Reddy, 2004, p. 19).

Com o fim do apartheid, o Congresso Nacional Africano, que ganhou as eleições e assumiu o governo da República, teve de conciliar objetivos diferentes e, por vezes, contraditórios na área do ensino superior. Proveniente da esquerda, em parceria com o Partido Comunista, o novo governo estava convencido da importância do planejamento e tinha uma visão funcionalista do ensino superior, que deveria contribuir para o desenvolvimento econômico do país. Ao mesmo tempo, o governo precisou dar prioridade não apenas a acabar 
com a legislação do apartheid, mas também ao desenvolvimento de políticas de redução do desequilíbrio entre brancos e negros no acesso ao ensino superior, principalmente nas instituições com mais recursos e de mais prestígio. Também foi preciso colocar mais recursos nas universidades negras, antes negligenciadas, o que exigiu mais recursos alocados ao ensino superior. Finalmente, embora o governo estivesse firmemente convencido da importância do planejamento e da centralização governamental, também houve fortes reivindicações da sociedade sul-africana por uma maior descentralização e a abertura para o jogo das forças de mercado não só no setor empresarial, mas também no ensino superior.

Uma das primeiras medidas do novo governo foi estabelecer um Departamento Nacional de Educação unificado, colocando as universidades sob uma mesma jurisdição e eliminando as barreiras raciais. Mas isso não significou que a segregação real tenha desaparecido. Instituições predominantemente brancas, como Stellenbosch, Cidade do Cabo e Rhodes, se mantiveram majoritariamente brancas, enquanto que alguns poucos brancos matricularam-se em instituições tradicionalmente negras. Havia razões culturais e geográficas para isso, mas a mais importante foi que o fim do apartheid não significou o fim das grandes diferenças econômicas e educacionais que existiam entre os brancos e a maioria da população negra, e simplesmente não havia candidatos negros em número suficiente que pudessem competir com os brancos nos processos de seleção das universidades mais prestigiadas. A ação afirmativa, com todos os seus prós e contras, tornou-se uma política central em todos os aspectos da República da África do Sul, reduzindo, em alguma medida, os desequilíbrios raciais, mas também provocando críticas, por

favorecer apenas o "topo" da população negra, e correndo o risco de tornar as credenciais de raça e identidade mais importantes que o mérito e a competência comprovados (Alexander, 2006).

Entre 1995 e 2012, o ensino superior na África do Sul aumentou de 500 mil para 900 mil, um crescimento pequeno, se comparado com o ocorrido no Brasil, na Índia ou na China. A taxa de participação é atualmente estimada em 17,7\% do grupo etário relevante, longe da expectativa oficial de 1995 de que atingiria 30\% em dez anos. Resumindo as principais tendências, Kirti Menon, observa que, “[...] entre 1994 e 2010, houve um crescimento de $200 \%$ de estudantes africanos. Apesar do crescimento, a taxa de participação de estudantes africanos foi de 12\% em 2011", e conclui que "o ritmo de crescimento da educação superior em relação ao crescimento da população, no grupo etário de 18 a 24 anos, não está de modo algum sincronizado. É claro que seria necessário um investimento maciço no ensino superior para sustentar o crescimento, embora não seja evidente que os fluxos de entrada provenientes do sistema escolar produziriam os resultados requeridos" (Menon).

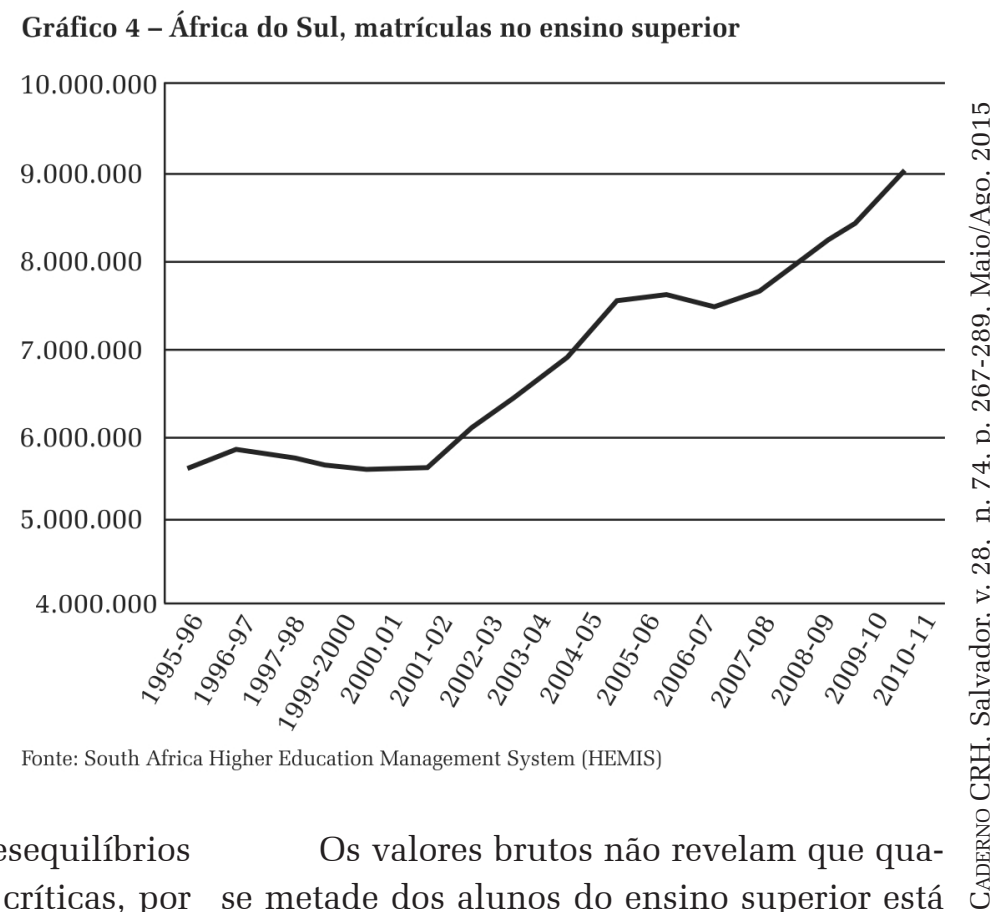


em programas de educação à distância, oferecidos, em sua maioria, pela Universidade da África do Sul, que ostenta um corpo discente de 350 mil alunos. As taxas de graduação têm sido muito baixas, e a maioria dos estudantes matricula-se em cursos voltados para profissões sociais, mais acessíveis financeira e academicamente, especialmente para estudantes que provêm de famílias pobres e menos instruídas. O investimento público no ensino superior não se alterou significativamente no período. Há um crescente debate no país sobre a fórmula de financiamento utilizada pelo governo para apoiar as instituições de ensino superior, bem como sobre as mensalidades cobradas dos alunos pelas universidades, com uma crescente demanda por ensino superior gratuito (Wangenge-Ouma, 2012).

Como em outros países em desenvolvimento, o ensino superior privado também cresceu na África do Sul nos últimos anos, embora não na mesma proporção do seu crescimento no Brasil ou na Índia. Citando fontes diferentes, Michael Cross mostra que

[...] o número de escolas particulares aumentou de 518 em 1994 para cerca de 1.500 em 2001, e mais de 100 mil estudantes matricularam-se em 145 instituições privadas de ensino superior, em 2004. O mercado de prestadores de serviços privados está L 2 concentrado principalmente em educação e formaจิ ção profissional, e restrito ao currículo comercial e $\dot{0}$ de administração e não representa qualquer concorrência significativa para o setor público.

Outra ocorrência importante foi a migração de profissionais sul-africanos altamenڤै

i. já que muitas pessoas deixaram a África do Sul por razões políticas e econômicas nos anos de apartheid, de acordo com o relatório, a emigra- ção aumentou a partir de 1994. Além disso, estimou-se que entre um oitavo e um quinto dos sul-africanos com educação de terceiro grau residem atualmente no exterior.

Para muitos que não deixaram o país, uma alternativa foi estudar em uma instituição privada. Como no Brasil, a maior parte do ensino superior privado na África do Sul tem fins lucrativos. Resumindo uma extensa análise do setor privado do país, Daniel C. Levy (2003) ressalta que

[...] as instituições privadas comercialmente bem sucedidas colocam os estudantes no cerne. Os alunos são consumidores com poder de escolha e dinheiro na carteira. Administradores e proprietários dirigem as instituições para atrair os alunos e, claro, para ganhar dinheiro através da eficiência. Isso deixa os professores, contratados em tempo parcial, mas, em tese, com valiosa experiência prática, sem o poder que costumam ter nas universidades clássicas. O seu papel é em, grande medida, se adaptar ao currículo e a outras práticas institucionais. A África do Sul não é líder mundial no ensino superior privado, no sentido de que outros países tenham procurado imitar seu exemplo. Mas fica perto da vanguarda das tendências globais em um ensino superior privado comercial que enfatiza os lucros e a orientação prática.

\section{BRASIL}

Sob o domínio português, de 1500 a 1822, o Brasil permaneceu praticamente um país de analfabetos, com exceção de um pequeno grupo de burocratas, comerciantes e sacerdotes. Ainda em 1950, 57\% da população de 5 anos ou mais era analfabeta. As primeiras instituições de ensino superior foram estabelecidas após a independência, no século XIX (um par de escolas de Direito, Medicina e Engenharia), e as primeiras universidades, em São Paulo e no Rio de Janeiro, datam da década de 1930. A educação básica pública começou em algumas capitais no final do século XIX e início do século XX, e a universalização do ensino primário só foi alcançada na década de 1990. 
Enquanto o governo federal se movia lentamente para criar suas próprias universidades públicas, alguns estados e grupos privados tomaram a iniciativa. O Estado de São Paulo, que concentra a maior parte da riqueza gerada pelas plantações de café e as primeiras indústrias, criou suas próprias escolas de Engenharia, Medicina, Agricultura e outras, já no final do século XIX, e organizou a primeira universidade do país em 1934, trazendo professores da Europa para ensinar e fazer pesquisa em ciências naturais e sociais. A Igreja Católica, que já estava envolvida no ensino básico e secundário, criou a sua primeira universidade na década de 1940 e, em muitos estados, as comunidades locais se organizaram para estabelecer suas próprias escolas de Direito, Medicina e Engenharia. Como mostra Clarissa Baeta Neves,

O Brasil passou por duas ondas de expansão das matrículas. O primeiro período de crescimento significativo ocorreu a partir de meados da década de 1960 até o início da década de 1980. As matrículas, em 1960, totalizavam apenas 93 mil estudantes, 55,9\% dos quais em instituições públicas. Em 1970, as matrículas saltaram para 425.478 alunos. Desse total, $49 \%$ estavam no setor público. Já em 1975, o número de matrículas foi de 1.072.548 estudantes, cerca de $62 \%$ deles no setor privado. Atualmente, o

Gráfico 5 - Brasil, matrículas no ensino superior - 1960-2011

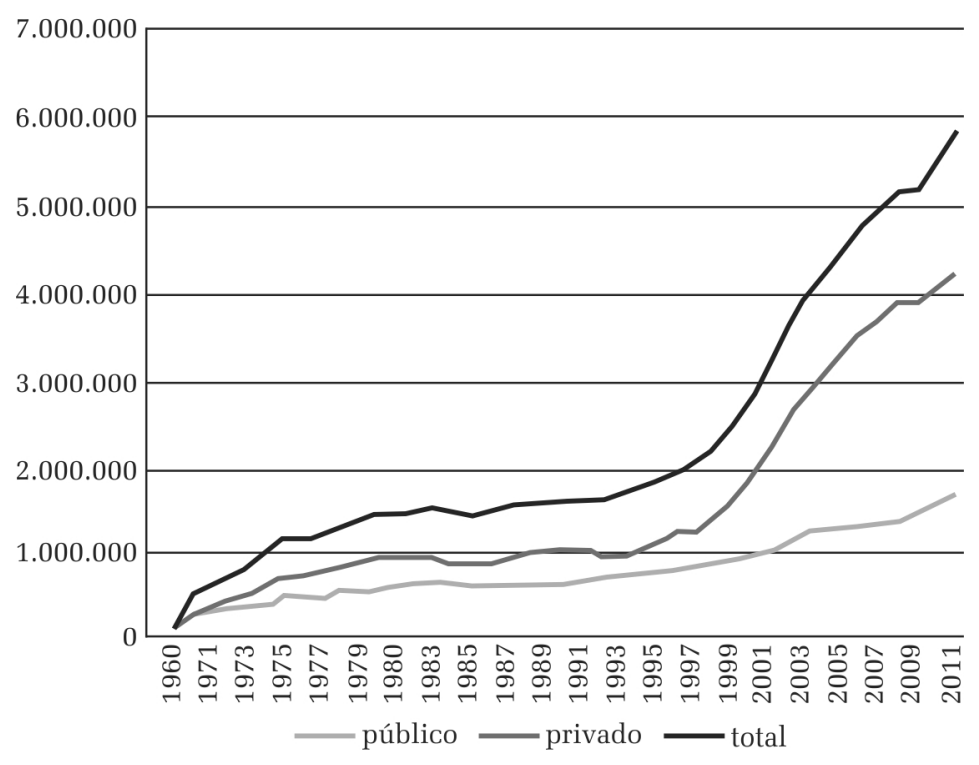

Fonte: Brasil, Ministério da Educação/INEP
Brasil tem cerca de 6 milhões de estudantes no ensino superior, $72 \%$ dos quais no setor privado.

A primeira tentativa do governo federal de estabelecer uma política para o ensino superior ocorreu na década de 1930, com o ambicioso projeto de criar uma Universidade Nacional, na capital federal, Rio de Janeiro, que poderia se tornar o modelo a ser replicado nos outros estados (Schwartzman; Bomeny et al., 2000). Depois de Segunda Guerra Mundial, com a nova onda de crescimento econômico e urbanização, o governo federal incorporou várias pequenas universidades criadas por governos estaduais e municipais nos anos anteriores (exceto São Paulo) e criou uma rede de universidades federais, que, junto com a expansão do setor privado, foi responsável pela primeira onda de expansão. Essas universidades deviam seguir o modelo organizacional criado inicialmente pela Universidade Federal do Rio de Janeiro, que logo se tornou apenas uma entre outras Universidades Federais. Esse modelo consistia, principalmente, de uma coleção de escolas profissionais nas áreas tradicionais de Direito, Engenharia, Medicina, Arquitetura, Odontologia e outras, e de Faculdades de Filosofia, Ciências e Letras, que deveriam preparar os professores para o ensino secundário e também para fazer pesquisas (o que, na prática, só ocorria na Universidade de São Paulo, em algumas escolas de Medicina no Rio de Janeiro e São Paulo, e em algumas instituições de pesquisa federais). A formação de professores para a educação básica era feita no nível secundário, em “escolas normais”, e, mais tarde, passou a ser feita pelas faculdades superiores de educação. Não havia colleges de formação geral, no sentido britânico ou americano, nem pós-graduação. Os professores universitários eram geralmente profissionais 
que davam aulas algumas horas por semana e obtinham a maior parte de sua renda em suas carreiras profissionais. Nas instituições públicas, no entanto, eles se tornaram funcionários públicos e, gradualmente, se organizaram para exigir igualdade de remuneração e outros benefícios trabalhistas.

A segunda reforma ocorreu em 1968, em um clima muito diferente. O Brasil estava, então, sob um regime militar, e a capital já mudada para Brasília. Nos anos anteriores, os estudantes universitários haviam participado de organizações de esquerda, e o governo decidiu que as universidades brasileiras deviam ser modernizadas. Com a ajuda de consultores norte -americanos (Atcon, 1966), o governo decidiu transformar as universidades brasileiras segundo o modelo americano, substituindo as antigas cátedras por departamentos acadêmicos, permitindo que os alunos estudassem por créditos em vez de seguir sequências rígidas de cursos, criando escolas de pós-graduação e exigindo dos professores que tivessem um diploma de doutorado, combinando pesquisa e ensino.

Um erro evidente da reforma foi tomar como modelo a universidade de pesquisa norte-americana, em vez de espelhar-se nas faculdades comunitárias (community colleges) ou numa combinação de ambas. Sob o novo sis$\stackrel{2}{\sim}$ tema, os estudantes continuaram ingressando nas escolas profissionais para programas de $\stackrel{8}{4}$ cursos com duração de quatro a seis anos, e só então podiam, eventualmente, entrar na pósgraduação, onde ela existisse. Os reformadores não consideraram que o Brasil não tinha profes-

\& criação apressada de programas de pós-gradua-

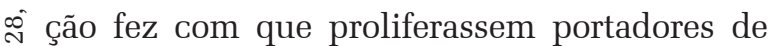

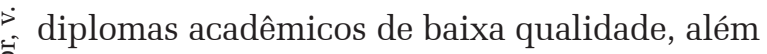
da contratação de professores "provisórios" que se tornaram efetivos em seus postos. O status de funcionário público, concedido a todo o pessoal acadêmico, tornou as universidades públicas brasileiras, de longe, as mais caras de toda a América Latina. Mas o erro mais grave foi não ter percebido que a demanda por ensino superior no Brasil estava prestes a explodir e não poderia ser atendida pelas poucas instituições públicas e caras que existiam. A solução foi limitar o acesso às universidades públicas por meio de exames de admissão muito competitivos, e permitir que o setor privado se expandisse sem muito controle.

O resultado da reforma de 1968 foi que o ensino superior brasileiro se tornou, no papel, unificado sob o modelo único da universidade de pesquisa norte-americana, mas, na prática, altamente estratificado. Algumas universidades chegaram mais perto do modelo ideal, mantendo a qualidade de suas escolas profissionais e, particularmente após o final dos anos 1970, criando programas de pós-graduação de boa qualidade no campo das ciências naturais e sociais. Esse grupo inclui algumas universidades federais e também as universidades estaduais de São Paulo, que são mais bem dotadas financeiramente, permaneceram independentes, mas adotaram o mesmo modelo. Também inclui, pelo menos, uma instituição privada, a Pontifícia Universidade Católica do Rio de Janeiro, que, por um tempo, contou com apoio federal para seus programas de pósgraduação e pesquisa. O segundo nível inclui a maioria das universidades federais e também universidades estaduais que nunca foram capazes de desenvolver a pós-graduação e trabalham principalmente como instituições de ensino. O terceiro grupo é formado por um grande número de instituições privadas, a maioria delas oferecendo cursos noturnos sobretudo nas profissões sociais (geralmente Direito, Administração ou Educação) a uma mensalidade baixa, e pagando seus professores por hora. Grandes organizações podem ser reconhecidas pelo governo como "universidades", enquanto que as menores ficam com o título de "faculdades" ou "escolas". Independentemente de sua propriedade e estatuto formal, todos os diplomas concedidos por essas instituições são igualmente válidos, de acordo com a legislação brasileira. Os alunos que têm uma formação 
melhor no nível do ensino secundário, geralmente de famílias mais ricas e com recursos para colocá-los em boas escolas particulares e pagar por cursos de treinamento, conseguem ter acesso às carreiras de maior prestígio nas melhores universidades públicas onde não pagam mensalidades. Os estudantes mais pobres, oriundos principalmente de escolas públicas de baixa qualidade e, muitas vezes, tendo de trabalhar durante o dia, só conseguem entrar nos cursos noturnos no setor privado, ou, no máximo, nos cursos menos competitivos em universidades públicas, em áreas como educação e serviço social.

Como mostra Maria Helena Magalhães Castro, a desconexão entre a legislação e a realidade criou um problema de regulação e de garantia de qualidade que nunca conseguiu ser resolvido. Desde os anos 1990, o Ministério da Educação tem tentado fazer com que o setor privado cumpra os requisitos formais do modelo de universidade de pesquisa, exigindo que tenha professores em tempo integral, com diplomas de pós-graduação e que faça pesquisa, exigências às quais a maioria não consegue atender (Castro, Maria Helena Magalhães). O Ministério da Educação também desenvolveu uma avaliação engenhosa para estudantes de graduação em diferentes áreas (Schwartzman, 2010), e usou esses resultados, juntamente com outros indicadores, para estabelecer um ranking de programas de cursos e universidades, ameaçando fechar os que têm baixo desempenho repetidamente. Tanto as universidades públicas como as privadas são submetidas às mesmas avaliações, mas, enquanto algumas instituições privadas foram, de fato, punidas com suspensão ou até fechadas, o Ministério tem se mostrado impotente ou desinteressado em lidar com suas próprias universidades, que são autônomas e criadas por lei.

Como na maioria dos outros países, a legislação brasileira assumiu que todas as universidades privadas eram sem fins lucrativos, ou filantrópicas, o que pode ter sido verdade para as universidades católicas e algumas ins- tituições de base comunitária, mas não era a realidade da maioria das instituições que surgiram desde os anos 1980 (Levy, 1986). O governo decidiu reconhecer esse fato e permitir que as instituições de ensino superior se declarassem com fins lucrativos, tornando-se, portanto, sujeitas à tributação, ao mesmo tempo em que exigiu que aquelas que permaneceram sem fins lucrativos demonstrassem sua natureza filantrópica. A consequência dessa legislação foi que o setor privado passou a consolidar-se em grandes conglomerados empresariais, seja através da compra de instituições menores ou da criação de novas. Alguns desses conglomerados tornaram-se empresas públicas com ações na bolsa de valores, atraíram grandes investidores nacionais e internacionais e adotaram modernas tecnologias de gestão e ensino para reduzir seus custos e padronizar seus produtos. Hoje, cerca de cinco dessas corporações detêm cerca de $20 \%$ das matrículas do ensino superior no Brasil. Elas são suficientemente poderosas para fazer lobby no Congresso e negociar com o Ministério da Educação para tornar sua regulamentação mais flexível e, se necessário, podem processar o Ministério.

Na década de 1990, as tentativas do Ministério da Educação de aumentar o controle sobre as universidades federais, tornando-as responsáveis pelo uso de seus recursos, e sobre o setor privado, tornando-o mais parecido com as instituições públicas, terminaram em fracasso. Depois de 2002, sob a presidência de Luiz Inácio Lula da Silva, o governo optou por alocar mais recursos e expandir as instituições públicas, e por criar um programa para isentar o setor privado de impostos em troca de bolsas de estudo para estudantes de baixa renda, o Prouni. Houve também a decisão de criar cotas para estudantes de baixa renda e não brancos em universidades públicas, em um esforço de corrigir as desigualdades sociais no acesso ao ensino superior.

Para ter uma noção da composição étnica da população brasileira, o Instituto de Geografia e Estatística no Brasil, responsável pelos 
Censos, pergunta como os entrevistados definem sua "cor" - branco, preto, pardo ou amarelo, essa última dividida em brasileiros nativos e orientais. Na Pesquisa Nacional por Amostra de Domicílios do IBGE de 2012, 46,2\% se definiram como brancos, $45 \%$ como pardos, 7,9\% como pretos, $0,6 \%$, como amarelos (orientais) e $0,3 \%$ como indígenas. Aqueles que se dizem brancos ou amarelos são, em média, mais ricos e mais escolarizados que aqueles que se autodefinem como pretos, pardos indígenas, diferenças que estão mais fortemente relacionadas com suas origens sociais e regiões de residência, que com a ascendência biológica (Parra; Amado et al., 2003).

Em 2012, o Supremo Tribunal Federal declarou que as cotas raciais eram constitucionais; no mesmo ano, o Congresso aprovou a legislação que exige que $50 \%$ das vagas em universidades públicas sejam reservadas a estudantes oriundos de escolas públicas, dando preferência a não brancos. Além disso, entre 2008 e 2011, o número de admissões nas Universidades Federais aumentou 50\%, sem, contudo, alterar muito a predominância numérica esmagadora do setor privado.

Os impactos dessas políticas recentes ainda estão sendo debatidos. Há queixas, por parte das universidades federais, de que foram

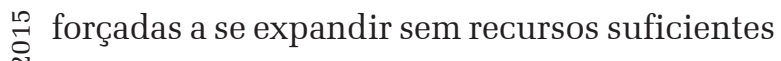

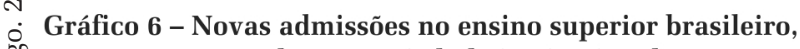
segundo a propriedade institucional e preparo, e não conseguem enfrentar o novo fluxo de estudantes e professores contratados com condições de trabalho que não correspondem aos padrões anteriores. Os defensores da ação afirmativa sustentam que o desempenho desses estudantes, uma vez admitidos, é semelhante ou até melhor que o dos admitidos pelos caminhos convencionais. Os críticos, por outro lado, argumentam que os cursos estão sendo forçados a baixar seus padrões acadêmicos, e que o uso oficial da raça na política pública vai contra os princípios constitucionais contra a discriminação, não obstante o parecer da Suprema Corte. Argumentam também que a melhor política para aumentar o acesso ao ensino superior de estudantes oriundos de famílias de baixa renda, que não podem conseguir uma boa qualidade de ensino secundário, seria fornecer-lhes apoio acadêmico e financeiro para que possam estudar em tempo integral e abrir mais alternativas de ensino técnico e profissional, que é muito limitado no Brasil e quase inexistente nas universidades federais.

Outra crítica é que, com toda a ênfase colocada sobre a questão popular de acesso, o governo tem negligenciado as questões da qualidade acadêmica, e não segue a linha de outros países, que estão investindo pesadamente em suas melhores universidades, para alcançar a excelência acadêmica internacional. Na verdade, as duas únicas universidades brasileiras que aparecem nos rankings internacionais, embora não em posições muito altas, são a Universidade de São Paulo (USP) e a Universidade Estadual de Campinas (Unicamp), ambas instituições estaduais que não foram afetadas pelas políticas do governo federal, e se beneficiam do generoso apoio do governo do estado. No entanto, os programas de pós-graduação e pesquisa no Brasil, mesmo quando sediados dentro das universidades, têm seu próprio sistema de avaliação e financiamento, e vêm apresen- 
tando resultados notáveis nos últimos anos, diplomando mais de 12 mil doutores por ano e aumentando a participação do Brasil em publicações científicas internacionais. Este setor não está imune a críticas - a produção de patentes é muito limitada, os níveis de citação são baixos, os vínculos entre a pesquisa e o sistema produtivo são pobres -, mas, ainda assim, a pesquisa e a pós-graduação brasileiras são, de longe, as maiores e mais desenvolvidas da América Latina.

A maioria dos cientistas de alto nível, nas universidades brasileiras, graduou-se nas universidades dos Estados Unidos e da Europa, graças a um fluxo constante de bolsas fornecidas pelo governo brasileiro, bem como de fundações internacionais e governos estrangeiros. Diferentemente dos outros BRICS, o Brasil não tem um problema significativo de fuga de cérebros, não há muitos estudantes que optam por ir para o exterior para seus estudos universitários, e a maioria dos que saem com bolsas acabam retornando. Mas o ensino superior brasileiro como um todo é muito isolado do fluxo internacional de estudantes, conhecimento e instituições. Todo o ensino é feito em português, há poucos estudantes estrangeiros, é difícil para um não brasileiro tornar-se professor permanente no país, e as universidades brasileiras, com exceção de algumas escolas de economia e negócios para a elite, não participam do mercado internacional de talento. Recentemente, o governo anunciou um ambicioso programa chamado "Ciência sem Fronteiras", que deveria enviar 100 mil brasileiros para estudar no exterior em quatro anos, o que gerou muito entusiasmo. No entanto, um exame mais atento mostra que esse programa é principalmente para estadias curtas, para alunos de graduação, com um grande número indo para Portugal ou Espanha, devido à sua incapacidade de falar inglês ou francês (Castro; Barros et al., 2012).

\section{CONCLUSÕES}

Este breve resumo das experiências dos países BRICS mostra que a maioria deles, com exceção do Brasil, lida com o crescimento por meio da diversificação formal de suas instituições, selecionando algumas para receber apoio adicional e atingir padrões de nível internacional, fazendo com que as outras sobrevivam com menos recursos públicos ou saiam para o mercado em busca de recursos; outro aspecto geral é a permissão da expansão de instituições de ensino superior privadas. Além disso, o ensino superior é normalmente dividido em dois grupos principais, um mais acadêmico, as universidades, e outro mais introdutório ou vocacional, as faculdades e institutos técnicos. No Brasil, apesar de a legislação exigir que todas as instituições de ensino superior devam aderir ao modelo humboldtiano de universidade de pesquisa, as instituições são extremamente diferenciadas, com algumas universidades de ponta e muitas instituições apenas de ensino; a grande maioria dos estudantes, no Brasil, encontra-se em instituições de ensino privadas, e o ensino vocacional não se desenvolveu. Outra tendência geral, nesses países, é a expansão da educação à distância, particularmente grande na África do Sul, onde a UNISA é a maior instituição em termos de matrículas, mas também cresce de forma constante em outros países.

Exceto novamente no Brasil, em todos os cinco países os estudantes pagam mensalidades nas universidades públicas, com a situação peculiar da Rússia, onde as instituições públicas combinam alunos selecionados através de concursos públicos, que estudam de graça, com outros estudantes que são admitidos com pagamento de mensalidade. Um pressuposto comum aos países do BRICS é que o ensino superior é um bem público que pode ajudá-los a se desenvolver, por meio da qualidade do seu capital humano, e também um direito que deve ser proporcionado pelo governo aos seus cidadãos. Não é fácil enquadrar 
o setor privado nesse cenário. Para a maioria dos países, a educação privada só pode existir com instituições filantrópicas sem fins lucrativos, um entendimento que faz sentido para as instituições religiosas ou comunitárias, mas não quando a oferta de educação superior se transforma em um empreendimento empresarial. Em todos os países, os governos tentam regular e impor padróes de qualidade para as instituições privadas, mas sem muito sucesso, e tanto o Brasil como a África do Sul aceitam que o ensino superior possa ser fornecido com fins de lucro. Isso levou à criação de empresas que proporcionam educação padronizada e de baixo custo a milhões de estudantes aos quais as instituições públicas não conseguem atender. O setor privado é muito grande na Índia e no Brasil, mas muito menor na Rússia, China e África do Sul.

Para lidar com a diversidade social dos estudantes, China, Índia, África do Sul e Brasil têm desenvolvido políticas de ação afirmativa para facilitar o acesso ao ensino superior de pessoas que provêm de segmentos mais pobres ou são minorias étnicas. A Rússia herdou da União Soviética uma história complexa e, por vezes, contraditória de políticas relativas a suas minorias nacionais, linguísticas e religiosas, mas atualmente não existe uma política กำ nacional de ação afirmativa no ensino superior (Roeder, 1991; Martin, 2001). Em todos os países, essas políticas são cercadas de controvérsias, com o reconhecimento de que, embora elas permitam um aumento no acesso ao ensino superior de membros de alguns grupos, criando oportunidades que não existiriam de ‡i outra forma, os beneficiários são, em sua maioria, pessoas que se encontram no topo de suas comunidades, deixando a desigualdade social em geral inalterada.

O pressuposto de que o ensino superior está se expandindo para fornecer capital humano mais qualificado para o desenvolvimento econômico e tecnológico é contestado pelo fato de que a maior parte do crescimento das matrículas ocorre no campo das ciências sociais, das humanidades e das profissões sociais, bem como em Educação, em vez de Ciência, Tecnologia e Engenharia. Até certo ponto, essa tendência corresponde ao fato de que, com exceção da China, o setor industrial está diminuindo de tamanho, enquanto o setor de serviços, incluindo educação e saúde, mostra um crescimento constante. Mas também reflete o fato de que muitos estudantes que chegam e têm acesso ao ensino superior são prejudicados por uma escolaridade muito fraca, e não conseguem seguir as exigências acadêmicas das profissões de base científica.

Finalmente, as questões da internacionalização têm estado muito presentes no debate sobre o ensino superior nos BRICS, mas os resultados não são muito notáveis. Apesar dos esforços, nenhum país conseguiu elevar as suas principais instituições às primeiras posições nos rankings internacionais, embora a China possa estar caminhando mais fortemente nessa direção. China e Índia têm o maior número de estudantes e pessoas de nível universitário que estudam e vivem no exterior, e são, até certo ponto, beneficiadas pelo conhecimento trazido por aqueles que retornam e também pelo estabelecimento de redes empresariais e acadêmicas entre residentes no país e aqueles no exterior. A África do Sul também tem um número considerável de estudantes e profissionais no exterior, particularmente na Inglaterra, mas não parece ser capaz de atraí -los de volta para vinculá-los mais fortemente às instituições locais e à economia. $\mathrm{O}$ Brasil tem uma tradição de enviar estudantes para estudos de pós-graduação no exterior e trazê -los de volta, sem uma diáspora significativa. A Rússia também viveu alguma diáspora com o fim da União Soviética, principalmente entre os judeus, mas, por outro lado, seu sistema de ensino superior é, em geral, autossuficiente (Altbach; Knight, 2007).

Ao se comparar a China com os outros BRICS, tem-se a impressão de que o crescimento e a mudança do ensino superior na China foram consequência de um planejamento 
cuidadoso, enquanto que, nos outros países, os governos estão, no máximo, tentando dirigir e gerenciar uma tendência mundial que está acontecendo independentemente de suas próprias iniciativas. É verdade que alguns países, e China em particular, mais do que outros, são capazes de influenciar essa tendência, mas, mesmo assim, a expansão do ensino superior tem sua própria dinâmica e não pode ser manipulada arbitrariamente.

Recebido para publicação em 12 de janeiro de 2015 Aceito em 15 de março de 2015

\section{REFERÊNCIAS}

AFRICAN NATIONAL CONGRESS. A policy framework for education and training. Pretoria: African National Congress, 1994. Disponível em: <http://www.anc.org.za/ show.php?id=263>

ALEXANDER, Neville. Affirmative action and the perpetuation of racial identities. In: Post-Apartheid South Africa. Transformation, v. 63-35, p. 92, 2006.

ALTBACH, Philip G.; KNIGHT, Jane. The internationalization of higher education: motivations and realities. Journal of studies in international education, v. 11, n. 3-4, p. 290-305, 2007.

ATCON, Rudolph P. Rumo à reformulação estrutural da universidade brasileira. Rio de Janeiro: Ministério da Educação. 1966.

BROWM, Phillip. The opportunity trap education and employment in a globalyeconomy. School of Social Science: Cardiff University, 2003.

CAI, Yuzhuo; YAN, Fengqiao. Demands and responses in chinese higherneducation. In: SCHWARTZMAN, S; PILLAY, P; PINHEIRO, R. (Ed.). Higher education in the Bricsscountries: investigating the pact between higher education andysociet . Springer, 2015.

CASTRO, Claudio de Moura; BARROS, Hélio et al. Cem mil bolsistas norexterior. Interesse Nacional, abr.jun., p. 25-36, 2012

CASTRO, Maria Helena Magalhães. Higher education policies in Brazil: a case of failure in marketnregulation. In: SCHWARTZMAN, S; PILLAY, P; PINHEIRO, R.(Ed.). Higher education in the Bricsscountries: investigating the pact between higher education andysociet. Springer, 2015.

COLLINS, Randall. The Credential Society. New York: Academic Press, 1979.

COUNCIL ON HIGHER EDUCATION. Size and shape taskmteam. Towards a new higher educationelandscape: meeting theyequity, quality and social development imperatives of South Africa in Ther 21st Century. Pretoria, 2000

CROSS, Michael. Staterpower, transition and new modes of coordination in higher education in South Africa. In: SCHWARTZMAN, S; PILLAY, P; PINHEIRO, R. (Ed.) Higher education in the Bricsscountries: investigating the pact between higher education andysociet. Springer, 2015.

DENG, Zhong; TREIMAN, Donald J. The impact of the cultural revolution on trends in educational attainment in the people's Republic of China. American Journal of
Sociology, v. 103, n. 2, p. 391-428, 1997

FROUMIN, Isak; KOUZMINOV, Yaroslav. Supply and demand patterns in Russian higher education. In: SCHWARTZMAN, S; PILLAY, P; PINHEIRO, R. (Ed.). Higher education in the Brics countries: investigating the pact between higher education and society. Springer, 2015.

GERBER, T. P.; SCHAEFER, D. R. Horizontal stratification of higher education in Russia:strends, gender differences, and labor market outcomes. Sociology of Education, v. 77, n. 1, p. 32-59, 2004. ISSN 0038-0407.

GIORDANO, Alfonso; TERRANOVA, Giuseppe. The Indian policy of skilled migration: brain return versus diaspora benefits. Journal of Global Policy and Governance, v. 1, n. 1, p. 17-28, 2012. ISSN 2194-7740.

HAWTHORNE, L. The growing global demand for students as skilled immigrants. Migration Policy Institute. Washington DC. 2008

HAYHOE, R. China's universities, 1895-1995: a century of cultural conflict. New York, London: Garland Publishing, Inc, 1996. ISBN 0203344804.

HEYNEMAN, S. Buying your way into heaven: the corruption of education systems in global perspective. Perspectives on Global Issues, v. 2, n. 1, 2007.

HOLLIS, M. Education as a positional good. Journal of Philosophy of Education, v. 16, n. 2, p. 235-44, 1982. ISSN 1467-9752.

JOHNSTONE, D. Bruce; ARORA, Alka; EXPERTON, W. The financing and management of higher education: a status report on worldwide reforms. The World Bank. Washingon, DC. 1998.

JOSHI, K. M. Higher Education, social demand and social equity in India. In: SCHWARTZMAN, S; PILLAY, P; PINHEIRO, R. (Ed.). Higher education in the Brics countries: investigating the pact between higher education and society. Springer, 2015.

JUDT, Tony. Postwar: a history of Europe since 1945. Penguin Books. Kindle Edition, 2006.

KAPLAN, Dave; MEYER, Jean-Baptiste; BROWN, M. Brain Drain: new data, new options. Trade and industry monitor, v. 11, n. 10-13, 1999

KAPUR, Devesh; MEHTA, Pratap Bhanu. Indian higher education reform: from half baked socialism to half baked capitalism. Center for International Development Working, Paper 13. 2004.

KLEIN, H. S. The colored freedmen in Brazilian slavery society. Journal of Social History, v. 3, n. 1, p. 30-52, 1969.

The atlantic slave trade. Cambridg, New York: Cambridge University Press, 1999. v. 2i, 234p. ISBN 0521460204 (hardcover). 0521465885 (pbk.).

LEVY, Daniel C. Higher education and the State in Latin America: Private Challenges to Public Dominance. Chicago: University of Chicago Press, 1986. ISBN 0226476081.

Profts and practicality: how South Africa epitomizes the global surge in commercial private higher education. State University of New York (SUNY) - Department of Educational Administration \& Policy Studies, University at Albany -SUNY, 2003.

LIVI-BACCI, M.; MAEDER, E. J. The missions of Paraguay: the demography of an Experiment. Journal of Interdisciplinary History, v. 35, n. 2, p. 185-224, 2004

MARTIN, Terry. The affirmative action empire: nations and nationalism in the Soviet Union, 1923-1939. Ithaca: Cornell University Press, 2001.

MENON, Kirti. Supply and demand of higher education in South Africa. In: SCHWARTZMAN, S; PILLAY, P; PINHEIRO, R. (Ed.). Higher education in the Brics countries: investigating the pact between higher education and society. Springer, 2015. 
NEAVE, Guy. Academic Drift: some views from Europe. Studies in Higher Education, v. 4, n. 2, p. 143-59, 1979. ISSN 0307-5079.

NEVES, Clarissa Baeta. Demand and supply for higher education in Brazil. In: SCHWARTZMAN, S; PILLAY, P; PINHEIRO, R. (Ed.). Higher education in the Brics countries: investigating the pact between higher education and society. Springer, 2015.

PARRA, F. C. et al. Color and genomic ancestry in Brazilians. Proc Natl Acad Sci U S A, v. 100, n. 1, p. 177-82, Jan 7 2003. ISSN 0027-8424 (Print).

PENG, C. Focus on quality, not just quantity. Nature, v. 475, p. 267, 2011.

POSEL, D. The apartheid project, 1948-1970. The Cambridge History of South Africa, v. 2, p. 319-68, 2011.

POSTIGLIONE, Gerard A., (Ed.) China's National Minority Education Culture, Schooling, and Development. New York, London: Falmer Pressed. 1999.

REDDY, Thiven. Higher education and social tranformation: South Africa Case Study. Johannesburg. Pretoria, Council for Higher Education, 2004.

ROEDER, Philip G. Soviet federalism and ethnic mobilization. World Politics, v. 43, n. 2, 1991.

RUMBLEY, Laura E.; PACHECO, Ivá N. F; ALTBACH, P. G. International comparison of cademic salaries: an exploratory study. Chestnut Hill, Massachusetts: Center for International Higher Education Lynch School of Education, Boston College, 2008.

SAUTMAN, Barry. Affirmative action, ethnic minorities and China's universities. Pacific Rim Law \& Policy Association, v. 7, n. 1, p. 77-116, 1998.

SCHOFER, Evan; MEYER, John W. The Worldwide Expansion of Higher Education in the Twentieth Century. American Sociological Review, v. 70, n. 6, p. 898-920, 2005. ISSN 0003-1224.

SCHWARTZMAN, Simon. The national assessment of courses in Brazil. In: Dill, D. D.; BEERKENS, M. (Ed.). Public Policy for Academic Quality - Analyses of Innovative Policy Instruments. Dordrech Heidelberg London New York: Springer, 2010. p. 293-12.
; BOMENY, Helena Maria Bousquet; COSTA, V. M. R. Tempos de Capanema. Rio de Janeiro: Paz e Terra / Fundação Getúlio Vargas, 2000.

SOUTH AFRICA, D. O. E. Education white paper 3: a Programme for the transformation of higher education. Pretoria: Department of Education, 1997. Disponível em: <http://www.che.ac.za/sites/default/files/publications/ White_Paper3.pdf $>$.

STELLA, Antony. External quality assurance in Indian higher education: case study of the national assessment and accreditation council (Naac). Paris: International Institute for Educational Planning, 2002.

TILAK, Jandhyala B. G. Policy crisis in higher education: reform or deform? Social Scientist, v. 38, n. 9-12, p. 61-90, 2010 .

TRILOKEKAR, Roopa Desaie EMBLETON, Sheila. The complex web of policy choices: dilemmas facing Indian higher education reform. In: SCHWARTZMAN, S; PILLAY, $\mathrm{P}$; PINHEIRO, R.(Ed.). Higher education in the Brics countries: investigating the pact between higher education and society. Springer, 2015.

VAN VUGHT, F. Mission diversity and reputation in higher education. Higher Education Policy, v. 21, n. 2, p. 151-74, 2008. ISSN 0952-8733

WANGENGE-OUMA, Gerald. Tuition fees and the challenge of making higher education a popular commodity in South Africa. Higher Education, v. 64, n. 6, p. 831-44., 2012

WEISSKOPF, Thomas E. Impact of reservation on admissions to higher education in India. Economic and Political Weekly, n. Sept. 25, p. 4339-49, 2004

WORLD BANK. Migration and remittances factbook 2011. 2. Washington, DC: The Workd Bank, 2010.

ZHA, Qiang; HAYHOE, Ruth. The Chinese model of development and the higher education policy. In: SCHWARTZMAN, S; PILLAY, P; PINHEIRO, R. (Ed.). Higher education in the Brics countries: investigating the pact between higher education and society. Springer, 2015 . 


\section{DEMAND AND PUBLIC POLICIES FOR HIGHER EDUCATION IN BRICS}

\author{
Simon Schwartzman
}

This article analyzes the expansion of higher education in so-called BRICS countries. The growing aspiration for higher education obliges governments to manage the operational costs of this system. The answers from each country varied with its history, culture and political regime. They all faced similar problems as lack of resources and political power of actors in the higher education system and beyond. Five dilemmas appeared to all countries: (1) expansion, equal access and diversification of enrollment, participation rates, the number and types of institutions; (2) financial constraints; (3) regulation of the private higher education; (4) how to make higher education institutions to provide more accountable to their students, employees and society as a whole; and (5) quality and social relevance of learning and research in higher education institutions. Using data and evidence of the latest research, the article shows common responses, with some exceptions in each case. Institutional diversification; affirmative action; growth of enrollments in the social sciences, humanities, social professions and education; little success in internationalization policies.

KEYwORDS: Higher Education. BRICS. Equal access. Financing higher education. Quality of higher education.

\section{DEMANDE ET POLITIQUES PUBLIQUES POUR L'ENSEIGNEMENT SUPÉRIEUR AUX BRICS}

\author{
Simon Schwartzman
}

Cet article analyse l'expansion de l'enseignement supérieur dans les pays dits BRICS. L'aspiration croissante de l'enseignement supérieur oblige les gouvernements à gérer les coûts de fonctionnement de ce système. Les réponses de chaque pays varient avec son histoire, la culture et le régime politique. Ils sont tous confrontés à des problèmes similaires tels que le manque de ressources et le pouvoir politique des acteurs du système de l'enseignement supérieur. Cinq dilemmes se présentent aux pays: (1) l'expansion, l'égalité d'accès et, les taux de participation, le nombre et les types d'institutions; (2) des contraintes financières; (3) la réglementation de l'enseignement supérieur privé; (4) la façon de rendre transparentes les institutions de l'enseignement supérieur; et (5) la qualité et la pertinence sociale de l'apprentissage et de la recherche dans les établissements d'enseignement supérieur. En utilisant les données des recherches les plus récentes, l'article montre des réponses communes, avec quelques exceptions dans chaque cas. Diversification institutionnelle; politiques de discrimination positive; la croissance des inscriptions dans les sciences humaines, les professions sociales et l'éducation; peu de succès dans les politiques d'internationalisation.

Mots-Clés: L'enseignement supérieur. BRICS. L'égalité d'accès. Le financement de l'enseignement supérieur. Qualité de l'enseignement supérieur.

Simon Schwartzman - Doutor em Ciência Política. Pesquisador do Instituto de Estudos do Trabalho e Sociedade no Rio de Janeiro. Foi Presidente da Fundação Instituto Brasileiro de Geografia e Estatística (IBGE) (1994-1998). Tem experiência na área de Ciência Política, com ênfase em políticas sociais, atuando principalmente nos seguintes temas: política comparada, educação superior, ciência e tecnologia, educação, e sociologia da ciência. É membro da Academia Brasileira de Ciências. Publicações recentes: Uses and abuses of education assessment in Brazil. Prospects (Paris), v. 43, p. 269-288, 2013; Ensino, formação profissional e a questão da mão de obra. Ensaio (Fundação Cesgranrio. Impresso), v. 21, p. 563623, 2013; Cem mil bolsas no Exterior. Interesse Nacional, v. 2, p. 25-36, 2012. 
